\title{
DIREITO CIVIL SANITÁRIO E O \\ Novo Código CIVIL
}

Daisy Gogliano(*)

\section{RESUMO}

O presente estudo trata do Direito Civil "como Direito Constitucional", por se constituir na essência do fenômeno jurídico. A velha dicotomia direito público e di eito privado - não encontra mais a sua razão de ser. 0 Direito Civil Sanitário, ou melhor, o Direito Civil da Saúde, tal como o denominamos de longa data, no seu caráter interdisciplinar, encontra hoje a sua tutela na Parte Geral no novo Código Civil brasileiro (Lei n. 10.406, de 10 de janeiro de 2002), que deverá entrar em vigor a partir de janeiro de 2003, na matéria dedicada aos direitos da personalidade ou direitos da pessoa humana, que pela primeira vez estão sendo introduzidos em nosso ordenamento. A saúde, bem jurídico fundamental, encontra o seu resguardo e a sua proteção não só na Carta Magna de 1988 como no novo Código Civil, no âmbito da proteção à integridade corporal (físico-psíquica) e notadamente em face das regras que informam os atos de disposição do próprio corpo, com efeitos diretos e importantes diante dos avanços tecnológicos e científicos da biomedicina, apresentando-se, assim, o Direito Civil da Saúde como um fenômeno unitário. É no Direito Civil que a saúde flue e se realiza como direito fundamental.

\section{Palavras-chave}

Direito Civil da Saúde, Direitos da personalidade e o novo Código Civil, Tutela da saúde, Integridade corporal.

(") Profa. Doutora do Departamento de Direito Civil da Faculdade de Direito da USP, Profa. Doutora dos cursos de pós-graduação, em nivel de especialização, do Cepedisa e Diretora Científica do Cepedisa. 


\section{ABSTRACT}

The present study deals with the Civil Law "as Constitutional Law", because it is constituted in the essence of the juridic phenomenon. The old dichotomy - public and private law - doesn't find its reason. The Sanitary Civil Law, better still, the Health's Civil Law, as we called for a long time, on its interdisciplinary character, finds nowadays its tutelage in the General Part of the new brazilian's Civil Code (Law n. 10.406, 10 ${ }^{\text {th }}$ january 2002), that should takes effect from january 2003, on in the discipline dedicated to the personality's rights or human person's rights, that have been introducing for the first time into our legal system. The health, fundamental juridical property, finds its protection not only in the Magna Charta of 1988, but even in the New Civil Code, in the protection's ambit of the corporal integrity (physicalphychic) and notably in face of the rules that inform the disposition acts of the own body, with direct and important effects in front of the technological and cientific advances on biomedicine, presentig, so, the Health's Civil Law as an unitary phenomenon. It's in the Civil Law that the health flows and happens itself as fundamental rule.

\section{Keywords}

Health's Civil Law, Personality's rights and the New Civil Code, Health's tutelage, Corporal integrity.

Sem qualquer indagação mais profunda, pode-se dizer que o Direito Civil situa-se à margem do Direito Sanitário, por se tratar, dentro da velha e cediça lição, do ramo do Direito que se ocupa primordialmente da família e da propriedade, portanto, de conteúdo eminentemente patrimonial, no qual a promoção da saúde, como bem jurídico fundamental e essencial do ser humano, não encontra lugar. Mesmo a expressão jus civile, isto é, direito dos cives, peculiar aos cidadãos romanos, que desfrutavam do status civitatis, não faz, por si só, que a saúde ocupe sua adequada posição, como fato social a que o Direito Civil deve promover, assegurar e desenvolver.

Sueli Gandolfi Dallari, pioneira do Direito Sanitário no Brasil, em 1988, justamente quando da elaboração da atual Constituição Federal, chamava a atenção para o caráter interdisciplinar do Direito Sanitário, a nova disciplina que surgia, como direito social por natureza, embora advertisse para o fato de que todo direito é social, colocando-o, como exemplo, ao lado do direito do trabalho e da segurança social.(1) A ilustre jurista assinala com a clareza que lhe é peculiar que "... atualmente, a saúde não tem apenas um aspecto individual que respeita apenas a pessoa. Não basta que sejam colocados à disposição dos indivíduos todos os meios de promoção, manutenção ou re-

(1) “Uma Nova Disciplina: O Direito Sanitário", in Revista de Saúde Pública. São Paulo, 22(4):327-34, 1988. 
cuperação da saúde para que o Estado responda satisfatoriamente à obrigação de garantir a saúde do povo. Hoje os Estados são, em sua maioria, forçados por disposição constitucional a proteger a saúde contra todos os perigos. Até mesmo contra a irresponsabilidade de seus próprios cidadãos. A saúde 'pública' tem um caráter coletivo. $O$ Estado contemporâneo controla o comportamento dos indivíduos no intuito de impedir-lhes qualquer ação nociva à saúde de todo o povo. E o faz por meio de leis". (2)

Observa Sueli Gandolfi Dallari que diante de todas essas atuações estatais orientadas para promover e garantir a saúde, tal como a saúde pública que se especializa como parte do direito administrativo, ante a supremacia do interesse público sobre o particular, como disciplina normativa, o ensino do Direito Sanitário deve, no seu entender, incluir outras áreas como: "Introdução à Filosofia e Sociologia do Direito Sanitário; Organização Jurídica da Administração Sanitária; Direito Penal Sanitário; Direito dos Serviços de Saúde; Direito do Planejamento Sanitário; Direito Previdenciário Sanitário; Direito Internacional Sanitário; Ética Sanitária; Polícia Sanitária e Direito Sanitário Comparado". (3)

E o Direito Civil Sanitário? Em que interessa a regulamentação dos interesses privados e particulares concernentes à garantia e à promoção da saúde como bem jurídico tutelado pelo Estado com a participação da sociedade? Se o Direito Civil, no seu significado técnico moderno, não se assimila ao direito dos cives que veio dos romanos, por abranger apenas as relações de direito entre os particulares, justamente por não fazer parte do direito público, não haveria como sustentar um Direito Civil da Saúde.

$\mathrm{Na}$ verdade, lembrando as palavras do saudoso $R$. Limongi França, "todo o direito nasceu do direito civil". Na verdade, o Direito Civil é a base de todo fenômeno jurídico, na feliz expressão de $R$. Limongi França, o qual nos legou um magnífico trabalho intitulado "O Direito Civil como Direito Constitucional", aula inaugural dos Cursos Jurídicos da Faculdade de Direito da Universidade de São Paulo, proferida em 4.3.1991, e sobre a qual discorremos a seguir, com breves pinceladas, dado o pequeno espaço de que dispomos no presente estudo, que visa a demonstrar a sempre e presente atualidade do Direito Civil, esquecida nos "manuais" que circulam pelos meios acadêmicos. Cada dia mais, passo e passo, o Direito Civil solta-se dos griIhões que o prendiam em torno da propriedade e da família, heranças burguesas do Código de Napoleão e dos surrados Códigos Europeus.

Sintetizando as palavras de $R$. Limongi França, "... o Direito Constitucional que se ensina nas Faculdades abrange basicamente a organização

(2) Idem, ibidem.

(3) Idem, ibidem. 
política do Estado, o qual, por sua vez, respeita ao que se poderia chamar pessoa jurídica do povo soberano". Acrescenta, que "o Direito Constitucional Contemporâneo, sucedâneo das leis fundamentais das polis gregas e dos fueros medievais, não deixa de ser realmente de natureza constitucional na medida em que define as bases, de um lado, do Direito Público, especialmente o chamado Direito Administrativo e, do outro, não propriamente a estrutura dos direitos subjetivos, mas a garantia da salvaguarda desses direitos, uma vez aí definidos, sem deixarmos de lado os impostergáveis preceitos implicitos das leis fundamentais".(4)

Entre os direitos fundamentais, a salvaguarda e garantia do bem juridico - saúde - encontra-se no Título "Da ordem Social", do o Capítulo "Da Seguridade Social", no art. 196 da Constituição Federal, em que: "A saúde é direito de todos e dever do Estado, garantido mediante políticas sociais e econômicas que visem à redução do risco de doença e de outros agravos e ao acesso universal igualitário às ações e serviços para a sua promoção, proteção e recuperação". Por se tratar de garantia fundamental, as ações e serviços de saúde são de relevância pública (art. 197 da CF).

Acentua R. Limongi França: "Não obstante, denominar 'constitucional' a lei fundamental da pessoa jurídica do Estado não deixa de ser consentâneo, porque, como se acenou, essa espécie de estatuto efetivamente concerne à base e, pois, à constituição dos fundamentais aspectos do Direito Público, especialmente o Administrativo, além de outros relativos ao Direito Social e ao Direito Privado". ${ }^{(5)}$

Entretanto, ensina R. Limongi França, "quando falamos de Direito Civil como Direito Constitucional, o enfoque não é o da hierarquia apriorística, senão do que concerne à essência do fenômeno jurídico, de tal modo que o valor hierárquico se apresenta, a posteriori, como uma conseqüência da necessidade que tem a generalidade das regras jurídicas, inclusive a própria Constituição Política, de atender aos preceitos impostos pelo Direito Civil, no que tange à vigência, à revogação e à aplicação da norma, além do que respeita ao conflito das leis no tempo e no espaço".(6)

Do mesmo modo, observa o saudoso civilista, "essas aludidas disciplinas e outrossim a própria Lei Magna estão adistritas aos ditames civilísticos concernentes a quanto diga respeito ao Fato e ao Ato Jurídico, não apenas relativamente à sua criação e desfazimento, como particularmente ao que concerne aos seus defeitos e nulidades".(7)

(4) In Revista de Direito Civil, Imobiliário, Agrário e Empresarial. Săo Paulo, 54:189-194, out./dez. 1990.

(5) Idem, ibidem, p. 192.

(6) Idem, ibidem, p. 193.

(7) Idem, ibidem, p. 193. 
Assim, a Lei de Introdução ao Código Civil, designada como legum legis, trata da aplicação de todas as Leis, inclusive da própria Constituição Federal. No que diz respeito ao Ato e Fato Jurídico, é na Parte Geral do Código Civil que encontramos "preciosíssimas regras alinhadas universalmente", das quais a Lei de Introdução e a Parte Geral "emergem, assim, como os dois estatutos definidores do próprio objeto fundamental de toda a Ciência Jurídica e de todas as disciplinas jurídicas por mais especializadas que sejam, a saber - o fenômeno jurídico. E se podemos dizer que aquela respeita à macrofenomenologia jurídica - ciência da Norma - esta última concerne à microfenomenologia - Ciência do Fato, aí incluso o Ato e o Negócio Jurídico".

Não é sem razão que todas as disciplinas jurídicas, todas elas inapelavelmente, como diz $R$. Limongi França, são oriundas da alma mater do Jus Civile Romanorum, inclusive as da Parte Especial do próprio Direito Civil.

Fundando-se na parêmia, jus et obligatio sunt correlata, $R$. Limongi França demonstra a relevância do Direito das Obrigações como Direito Constitucional, como a outra face da microfenomenologia, pois, a cada direito subjetivo corresponde uma obrigação cujo cumprimento se pode exigir mediante a provocação da tutela do Estado, por meio dos seus poderes estruturais, no caso, o judiciário com a sanção do Executivo.

Ademais disso, a Norma e o Fato Jurídico são as causas do Fenômeno Jurídico, revelando como fontes das obrigações a Lei e o Contrato. Considerando o dúplice aspecto macro e microscópico do Fenômeno Jurídico, em que "se manifesta por meio de realidades de duplo enfoque, nas quais de um lado está o Direito e do outro a Obrigação, e, via de conseqüência, é de se ponderar que todo o Direito Obrigacional, com as mais diversas modalidades das obrigações, assim como por meio das maneiras pelas quais se criam, modificam e extiguem, resultam numa continuação da Parte Geral do Código Civil, e, pois, num aspecto complementar do Direito Civil como Direito Constitucional". ${ }^{(8)}$

Indo mais além, trazemos o magistério de um renomado constitucionalista italiano Temistocle Martines, que em seu "Diritto Costituzionale"(9) exprime com clareza a relevância do fenômeno jurídico e do fenômeno associativo, em que os interesses do grupo social tende a se sobrepor aos interesses do grupo individual e coletivo. Os interesses individuais revelam-se puramente egoísticos, os quais só podem ser satisfeitos sob a forma associativa, ou seja, como interesses coletivos. Assim, o direito apresenta-se como um fenômeno unitário, no qual o fim último do direito é a conservação do

(8) In Revista de Direito Civil, Imobiliário, Agrário, e Empresarial. São Paulo, 54:189-194, out./dez. 1990.

(9) Diritto Costituzionale. Milano: Giuffrè, 1990, p. 41. 
grupo social, em que toda a norma é predisposta para assegurar esse fim. A velha distinção entre direito público e direito privado, distinção esta que não apresenta mais a sua razão de ser, torna-se inócua, pois, como assevera Martines, o fim próprio do direito "è la conservazione della società, quando una norma tutela un interesse che realizza in via immediata questo fine, detta norma è di diritto pubblico; quando, invece, una norma tutela in via diretta un interesse individuale e solo indirettamente un interesse pubblico, detta norma è di diritto privato". Citando Pugliatti, demonstra que as zonas do domínio do direito público e do direito privado dizem respeito ao caráter prevalente dos interesses em conflito. Depende, portanto, da natureza dos interesses tutelados, em que os interesses coletivos assumem relevância intermediária entre os interesses privados - egoísticos e os interesses de caráter geral.

Fala-se, hoje, em verdadeiro fenômeno de "publicização" ou "socialização" do direito privado, como também, inversamente, da "contratualização" ou "privatização" do direito administrativo, em que cada vez mais a tendência é fazer valer a esfera da autonomia da pessoa humana, isto é, do privado, com o intuito cada vez mais forte de proteger o "mais fraco", o hiposuficiente, o mais débil, em uma sociedade cada vez mais "publicizada" na estrutura normativa, que se contrapõe a uma sociedade sempre mais autônoma na sua estrutura atinente à pessoa. Em uma sociedade de massa, a dicotomia público/privado não apresenta mais qualquer interesse prático, porque a "organização é elemento essencial de todo grupo social", ${ }^{(10)}$ eis, que a própria família se organiza como "sociedade natural", ou seja, entidade familiar sob a proteção do Estado, articulando-se em multiplicidade de tipos.

Vicente Ráo, em sua clássica obra "O Direito e a Vida dos Direitos",(11) invocando o magistério de Georges Ripert - que repele a tendência moderna de "publicização" do direito privado, substituída pelos políticos por outro neologismo, a "socialização do direito", como se o direito somente agora se revelasse uma ciência social - , demonstra a técnica usada pelos inovadores: "O direito social designa o conjunto de regras que asseguram a igualdade das situações apesar das diferenças de fortunas, regras que socorrem os mais fracos, desarmam os mais poderosos e organizam a vida econômica segundo os princípios da justiça distributiva. Ora, para se alcançar esse resultado, preciso é recorrer-se a uma força superior a todos, ou seja, à força do Estado; e se esta força intervém nas relações privadas, o direito privado não pode deixar de ceder o passo às regras do direito público. A publicização é, pois, o meio de tornar social o direito".(12)

(10) Idem, ibidem, pp. 43-44.

(11) São Paulo: Resenha, 1976, vol. I, t. II, p. 188.

(12) Idem, ibidem, p. 188. 
Mas, torna-se imperioso observar que não se trata de uma "socialização" do direito privado imposta pelo Estado no sentido de sacrificar a autonomia privada, sobrepondo-se um interesse do Estado, aos moldes do Estado autoritário, com fins eminentemente políticos.

Quando se fala no "Direito Civil como Direito Constitucional", tal expressão vem na verdade, segundo a lição de $R$. Limongi França, reforçar um verdadeiro movimento inverso, justamente por ser o Direito Civil a base do fenômeno jurídic.o. Esse movimento inverso vem garantir o Estado de Direito, justamente no sentido de coibir a intervenção desordenada do Estado nas relações privadas, em que a internormatividade se faz presente.

A saúde, no Direito Civil, é bem jurídico da personalidade. Na Constituição Federal, segundo os ditames do seu art. $6^{2}$, são considerados direito social entre os demais direitos sociais, como educação, o trabalho, o lazer, a segurança, a previdência social, a proteção à maternidade e à infância e a assistência ao desamparado.

Por sua vez, como direito subjetivo, a saúde é consagrada no art. 196 da Carta Magna como "direito de todos e dever do Estado", que deve ser garantida mediante políticas sociais e econômicas.

A promoção, a proteção e a recuperação da saúde implicam, em plano constitucional, a participação da comunidade voltada às ações e serviços públicos de saúde. Por outro lado, a assistência à saúde, antes privativa do Estado, é livre à iniciativa privada, em que as instituições privadas podem participar de forma complementar do Sistema Único de Saúde, mediante diretrizes do próprio sistema único, mediante contrato de direito público ou convênio (art. 199 e parágrafo único da CF).

Com a proliferação dos planos de saúde, na forma de "convênios-médicos" e "seguros-saúde", na contratação de massa, em oferta pública, em que a saúde, na realidade, tornou-se um bem de consumo, posto à venda como outro produto qualquer, na chamada medicina "pré-paga", não bastaram para sua regulamentação as regras do Código de Defesa do Consumidor, tornando-se imperioso a proteção do Estado, ante a intervenção cada vez mais presente da Agência Nacional de Vigilância Sanitária - ANVISA e da Agência Nacional de Saúde - ANS, justamente para coibir os abusos dos contratos de adesão, impondo diretrizes à autonomia privada.

Ora, tais diretrizes, que interferem na contratação, regem-se pelas normas do Direito Privado, em razão de as empresas ofertarem aquilo que é um direito social, uma garantia constitucional, dentro de uma atividade que é complementar ao Sistema Único de Saúde. É nesse ponto que toda a atividade privada que tenha por objeto um direito social, complementar à atividade Estatal, apresenta características híbridas, ou seja, internormativas, conforme o interesse diretamente visado. 
Sueli Gandolfi Dallari demonstra com clareza que a reivindicação do "Direito à Saúde" encontra-se agregada ao rol dos "Direitos Humanos", embora sua reivindicação seja imemorial. ${ }^{(13)}$

Ora, é tão imemorial que integra, como bem jurídico, a categoria dos "Direitos Privados da Personalidade", ou seja, os direitos fundamentais e essenciais do ser humano, sob a ótica do Direito Privado e que antecederam as "Declarações dos Direitos Humanos". Essa categoria de direitos desenvolveu-se, principalmente, nos albores do século XIX, notadamente, na Alemanha com Köhler, denominando-os "direitos individuais", Windscheid, "direitos sobre a própria pessoa", Wachter, "direitos pessoais" e Gierke utilizando a expressão "direitos da personalidade".

Em quase todos os Códigos Civis europeus encontram-se na Parte Geral, como arcabouço do Direito Civil, disposições que tutelam a pessoa nos seus mais variados aspectos e prolongamentos, como direitos subjetivos privados, no sentido de resguardar a pessoa humana de toda e qualquer ofensa à sua integridade corporal (física e psíquica), moral e intelectual. Direitos estes que floresceram com o advento da idéia de direito subjetivo, principalmente com Donellus (Hugo Doneau) e Samuel Strick, expoentes da escola do Usus Modernus, na Alemanha, que em sua Dissertationun Juridicarum Francofurtensium (1675) alude ao Jus hominis in se ipsum, ou, potestas in se ipsum, no seus aspectos: De jure hominis in corpus; De jure hominis in animam; De jure hominis in faman e De jure hominis in vitam. ${ }^{(14)}$

Conceituamos os direitos da personalidade como os direitos subjetivos particulares, que consistem nas prerrogativas concedidas a uma pessoa pelo sistema jurídico e asseguradas pelos meios de direito, para fruir e dispor, como senhor, dos atributos essenciais da sua própria personalidade, de seus aspectos, emanações e prolongamentos, como fundamento natural da existência e liberdade, pela necessidade da preservação e resguardo da integridade física, psíquica e moral do ser humano, no seu desenvolvimento. ${ }^{(15)}$

Além do caráter privado desses direitos, que não se confundem com os direitos do homem e do cidadão, em seu aspecto público, recebendo a tutela constitucional, embora muitos desses direitos, como a vida, a saúde, a liberdade etc., também estejam erigidos à categoria de direitos fundamentais, os direitos da personalidade apresentam características próprias, delineadas pelo Direito Civil, no sentido de que são absolutos, em face de sua

(13) Op. cit., p. 327

(14) ApudGOGLIANO, Daisy. Direitos Privados da Personalidade. São Paulo: FADUSP, 1982, p. 79.

(15) GOGLIANO, Daisy. Op. cit., p. 363. 
oponibilidade erga omnes, vitalícios e necessários, não-pecuniários ou extrapatrimoniais, intransmissíveis, imprescritiveis e impenhoráveis.

No magistério de Orlando Gomes, "os direitos de personalidade são direitos subjetivos privados, destinada sua proteção, como é, a assegurar o desenvolvimento e a expansão da individualidade física e espiritual da pessoa humana".

"No entanto, como alguns desses direitos são públicos, vistos de outro ângulo, e outros se achem igualmente tutelados na esfera penal, necessário se torna definir, em termos claros, sua natureza privada." ${ }^{\text {(16) }}$

E acrescenta o autor: "Os direitos da dupla face, pública e privada, apresentam-se na esfera do Direito Civil quando se concretizam numa relação jurídica entre particulares sob a forma de uma obrigação contraída por seu titular voluntariamente, ou imposta pela lei a quem os viola, cometendo ato ilícito. Evidentemente compreendem faculdades de atuação, mas, enquanto não são atingidos permanecem como potencialidades, naquela esfera em que passam despercebidos ou simplesmente se revelam como simples poderes individuais". ${ }^{(17)}$

Em matéria de Direito Civil Sanitário, essa categoria de direitos assume real importância na preservação, tutela e resguardo da saúde, nos atos de disposição do próprio corpo, no que diz respeito à incolumidade do próprio corpo (vivo ou morto), ou seja, a integridade física, psíquica, moral e intelectual do ser humano, no qual o direito à vida revela-se essencial, de onde defluem todos os demais direitos. No âmbito dos direitos privados da personalidade, utilizando a expressão de Tomás de Aquino, "a saúde considera-se a forma do corpo". Pessoa e personalidade são conceitos inseparáveis. Toda ofensa à personalidade é ofensa à pessoa.

É norma assentada, de especial importância, que os direitos da personalidade não comportam limitação voluntária. Todo ato ou negócio jurídico que tenha por objeto a saúde, como bem jurídico da personalidade, não pode comportar qualquer limitação que possa comprometer a integridade da pessoa humana. Essa regra assume especial importância em todos os negócios que envolvam o corpo humano, vivo ou morto.

É o que se vê, em quase todos os diplomas civis modernos. Na Alemanha, o BGB, cuja vigência data de $1^{2} .1 .1900$, ao tratar das pessoas naturais em sua inviolabilidade, prevê uma tutela indireta, contida em seu § 823-I, no âmbito da responsabilidade civil, que dispõe: "Quem, por dolo ou negligência, lesar, antijuridicamente, a vida, o corpo, a saúde, a liberdade, a proprie- 
dade ou qualquer um outro direito de uma pessoa, estará obrigado, para com essa pessoa, à indenização do dano daí resultante".

A regra acima, contida na primeira parte do $\S 823$ refere-se ao "Direito geral da personalidade", como bens que estão indissoluvelmente unidos à pessoa, sob proteção absoluta, vale dizer, erga omnes, cujo sujeito passivo é universal.

Por sua vez, na França, a construção dessa categoria de direitos é pretoriana e a doutrina é rica e abundante, destacando-se os trabalhos e as obras de M. Perreau (1909); Marcel Planiol, em seu "Traité", Colin e Capitant, Marty e Raynaud, Josserand, Pierre Kaiser e tantos outros.

O Código Civil italiano de 1942 desempenhou um papel muito importante, como assevera Fábio Maria de Mattia, ${ }^{(18)}$ "pois serviu e continua servindo de modelo a muitas legislações. Historicamente, é o primeiro Código a tratar dos direitos da personalidade em vários artigos", realçando-se a regra que disciplina os atos de disposição do próprio corpo, em seu art. $5^{9}$ que tem servido de modelo em muitas legislações: "Gli atti di dispozione del proprio corpo sono vietati quando cagionino uma diminuzione permanente della integrità física, o quando siano altrimenti contrari alla legge, all'ordine pubblico o al buon costume".

Este preceito está garantido constitucionalmente, dentre os princípios fundamentais da Constituição da República italiana, em que "a saúde é tutelada como fundamental direito do indivíduo e interesse da coletividade" (pp. 32-1), inseridos entre os direitos e deveres do cidadão, sob o título "Rapporti Civili", estabelecendo, ainda: "Nessuno puó essere obligatto a un determinato trattamento sanitario se non per disposizione di legge. La legge non può in nessuno caso violare $i$ limiti imposti dal rispetto della persona umana".

Como se vê, a tutela da pessoa humana e da saúde encontra-se prevista tanto na lei ordinária como na constituição, preceitos estes dirigidos não só ao legislador como ao aplicador do Direito, sob a epígrafe Rapporti Ético-Sociali.

Observa-se que a Constituição italiana refere-se a qualquer tipo de tratamento sanitário, não se circunscrevendo a tratamento médico, de âmbito mais restrito como fazem muitas legislações. O vocábulo "sanitário" é o que comporta toda e qualquer ação que tenha por objeto a prevenção, promoção e recuperação da saúde, envolvendo não só os atos médicos, por excelência, como aqueles que são ministrados por agentes de saúde, em amplo aspecto.

(18) Direitos da Personalidade II. In Enciclopédia Saraiva do Direito. São Paulo: Saraiva, (28): pp. 147-65. 
O legislador italiano admite dentro de certo limite à disposição do direito à integridade física mediante o consentimento. Mas o consentimento encontra seu limite na lei, na ordem pública e nos bons costumes e desde que a diminuição da integridade física não produza uma diminuição permanente.

Por outro lado, na interpretação do dispositivo contido no art. $5^{\circ}$ do Código italiano, entendem os doutrinadores que a intervenção cirúrgica que tenha por objeto, na preservação da saúde, uma diminuição permanente da integridade física é lícita, cujo dano é justo, como, v.g., a amputação de um membro gangrenado.

O atual Código Civil português (Decreto n. 47.344, de 25.11.1966), igualmente, na Parte Geral, cuida especialmente dos "Direitos da Personalidade", consagrando em seu art. 70 a tutela geral da personalidade: 1 . A lei protege os indivíduos contra qualquer ofensa ilícita ou ameaça de ofensa à sua personalidade física ou moral. "2. Independentemente da responsabilidade civil a que haja lugar, a pessoa ameaçada ou ofendida pode requerer as providências adequadas às circunstâncias do caso, com o fim de evitar a consumação da ameaça ou atenuar os efeitos da ofensa já cometida."

O diploma português, avançado em muitos aspectos, traça os limites da disposição voluntária aos direitos da personalidade como regra geral, imposta como direito absoluto a todos, consoante o disposto no seu art. 81, a saber: "1. Toda a limitação voluntária ao exercício dos direitos da personalidade é nula, se for contrária aos princípios da ordem pública". "2. A limitação voluntária, quando legal, é sempre revogável, ainda que com a obrigação de indenizar os prejuízos causados às legítimas expectativas da outra parte."

A tutela geral da personalidade no Código Civil português é mais ampla do que a que se apresenta no Código Civil italiano, justamente por considerar NULA toda limitação contrária aos princípios de ordem pública, ou seja, os princípios que interessam à toda coletividade, ao mais altos interesses da coletividade. Por outro lado, aos moldes do diploma italiano, exclui da tutela a integridade psíquica, moral e intelectual.

Em nosso País, lamentavelmente, o Código de Beviláqua não traz a tutela dos Direitos da Personalidade na Parte Geral. Mas tal fato foi suprido pela doutrina e pela jurisprudência, como sucede na França, sobressaindo o pioneirismo de Orlando Gomes, Pontes de Miranda e $R$. Limongi França, ao lado de muitos doutrinadores que nos brindaram com artigos especializados sobre a matéria, sem olvidar Antonio Chaves que se dedicou aos atos de disposição do próprio corpo e à integridade psíquica. 
No que tange ao direito "constituendo", Orlando Gomes, no seu "Projeto de Código Civil", brindou-nos com os "Direitos da Personalidade", na Parte Geral.

Em seu Relatório, a Comissão, com a participação de Caio Mário da Silva Pereira e sob a presidência de Orosimbo Nonato e como relator o próprio Orlando Gomes, assim justifica: "Inclui-se a disciplina dos direitos da personalidade (arts. 28 a 36) no pressuposto de que sua proteção constitui indispensável complemento ao sistema de tutela constitucional dos direitos do homem, organizado nos países democráticos. Procura o Projeto dar solução a problemas que se tornam graves em razão do progresso científico e técnico, adotando critério que concilia a liberdade individual com as necessidades sociais, e sem esquecer os perigos e danos que esse progresso pode trazer à pessoa humana".

No que diz respeito aos atos de disposição do próprio corpo, vivo ou morto, incluindo o tratamento médico e o exame médico, além da perícia médica, vislumbramos no Projeto todos os princípios gerais que informam os direitos da personalidade.

$\mathrm{Na}$ tutela geral da personalidade, $\mathrm{O}$ art. 28 prescreve: "O direito à vida, à liberdade, à honra e outros reconhecidos à pessoa humana são inalienáveis e intransmissíveis, não podendo seu exercício sofrer limitação voluntária”. Aos moldes do Código Civil alemão, reconhece amplamente, em numerus apertus, "outros" direitos da personalidade. Por sua vez, acompanhando o Código Civil italiano e o português (na ocasião o seu projeto), prescreve que o exercício dos direitos da personalidade não pode sofrer limitação voluntária, isto é, contratual, cerceando, assim, a autonomia privada, na matéria.

Não alude aos atos que contrariem a ordem pública e os bons costumes, como faz o diploma civil italiano e muito menos considera nulos os atos de disposição que impliquem limitação voluntária aos direitos da personalidade e que contrariem a ordem pública, como preceitua o Código Civil português.

Quanto ao tratamento médico, art. 32 do Projeto, Orlando Gomes prevê: "Ninguém pode ser constrangido a submeter-se a tratamento cirúrgico, ou a tratamento médico com o risco de vida". Embora toda cirurgia envolva risco de morte, considerando a ocasião em que o Projeto foi aprovado (1964), ante os tímidos avanços da Medicina, outrora indiscutível e sagrada, a exegese do dispositivo, na verdade, diz respeito à experimentação humana.

No que concerne ao exame médico, em seu art. 33, assim está disposto: "Se alguém se recusar a exame médico necessário, não terá direito a aproveitar-se de sua posição". 
Tal preceito encontra ressonância nos dias atuais, com a aplicação dos exames de DNA em casos de investigação de paternidade, em que não se pode constranger o "possivel pai" a submeter-se à investigação genética. No entanto, ante a recusa, milita em seu desfavor a presunção da paternidade, não podendo se aproveitar de sua oposição. O mesmo sucede no caso da perícia médica, em que 0 art. 34 do Projeto Orlando Gomes assim prescreve: "A recusa à perícia médica ordenada pelo Juiz poderá suprir a prova que se pretendia obter com o exame".

Importa tecer pequenas considerações sobre o novo Código Civil, Lei n. 10.406 , de 10 de janeiro de 2002, em vacatio legis pelo prazo de um ano, recentemente sancionado. Em muitos aspectos apresenta retrocesso. A regra geral, contida no art. 11, deixa de assentar os princípios gerais que informam essa categoria de direitos, ou seja, não só intransmissíveis e irrenunciáveis, como imprescritíveis e inalienáveis em muitos dos seus aspectos.

Dispõe o art. 11: "Com exceção dos casos previstos em lei, os direitos da personalidade são intransmissíveis e irrenunciáveis, não podendo o seu exercício sofrer limitação voluntária".

Ao prever - com exceção dos casos previstos em lei -, o atual Código aprovado deixa uma abertura nitidamente perigosa ante os avanços científicos e tecnológicos que Orlando Gomes não deixava de advertir. Perde o seu caráter absoluto, de oponibilidade erga omnes, justamente em razão de o seu exercício não poder sofrer limitação voluntária, como princípio geral.

Contraditório em muitos aspectos, o novo Código, ao tratar dos atos de disposição do próprio corpo, preceitua em seu art. 13: "Salvo por exigência médica, é defesa o ato de disposição do próprio corpo, quando importar diminuição permanente da integridade física, ou contrariar os bons costumes". O atual Código Civil, recém-aprovado, ignora os avanços da biomedicina, em que não há que se falar em "exigência médica" como exceção aos atos de disposição do próprio corpo, principalmente em face da experimentação humana e da biotecnologia.

Em linhas gerais, toda a ofensa, todo o atentado aos direitos privados da personalidade, bem como toda a ameaça de lesão terão repercussão no campo da responsabilidade civil.

O Direito Civil Sanitário, no seu caráter internormativo, como discorremos linhas atrás, cada vez mais se faz presente, notadamente diante da bioética que se vislumbra como uma nova ciência, a questionar sempre sobre o que é lícito ou ilícito, em todos os atos de disposição do próprio corpo. 
Cumpre, portanto, ao Direito Civil da Saúde estabelecer nitidamente os lindes e os limites dos preceitos morais e jurídicos, levando em consideração que o Direito é o mínimo ético.

Em matéria de responsabilidade civil médica, novos aspectos se impõem, não só em razão da prestação de serviços médicos, mas de biomedicina, em que o Código de Defesa do Consumidor sempre fala mais alto. É o que observamos na responsabilidade civil que envolve a prestação de serviços médicos por parte das empresas que fornecem "planos de saúde", em atividade complementar à prestação de serviços públicos de saúde, cujo objeto é imediatamente a saúde da população, bem jurídico considerado "direito social" e que não pode permanecer à mercê da autonomia privada, pois, consoante a regra contida no CDC, em seu art. 14, "o fornecedor de serviços responde, independentemente da existência de culpa, pela reparação dos danos causados aos consumidores por defeitos relativos à prestação dos serviços, bem como por informações insuficientes ou inadequadas sobre sua fruição e riscos". Por outro lado, a exceção contida no $\S 4^{2}$, do aludido artigo, deve ser vista com cautela, pois comungamos da opinião de Antonio $H$. V.e Benjamim, que esclarece: "Por profissional liberal há que se entender o prestador de serviço solitário, que faz do seu conhecimento uma ferramenta de sobrevivência. É o médico, o engenheiro, o arquiteto, o dentista, o advogado. Trata-se, por outro lado, de categorias em franco declínio, na exata proporção em que mais e mais tais profissionais tendem a se agrupar em torno de empresas prestadoras de serviços: os hospitais, os grupos de saúde, as empresas de engenharia e de consultoria, as sociedades de advogados". Esse tratamento diferenciado faz que a teoria da culpa se aplique "apenas ao próprio profissional liberal, não se estendendo às pessoas jurídicas que integrem ou para as quais preste serviço". (19)

O fato é que a expressão "liberal" deve ser vista com cuidado. Não é profissional liberal aquele profissional médico que exerce a sua arte e profissão subjugado pelas imposições das empresas de "saúde privada", em detrimento dos usuários de serviços de saúde. No momento em que a medicina deixa cada vez mais de ser arte para se tornar uma simples técnica, a relação médico-paciente deve ser revista sob novas imposições jurídicas, em que a responsabilidade é objetiva, independentemente de culpa.

A tradicional responsabilidade civil médica assume novos aspectos. Em face da biotecnologia, da medicina preditiva, da reprodução assistida, da manipulação genética, da telemedicina, das cirurgias de transplantes de

(19) ApudMANCUSO, Rodolfo de Camargo. Manual do Consumidor em Juizo. São Paulo: Saraiva, 1994, p. 51. 
órgãos cada vez mais sofisticadas, com a utilização de avançadas técnicas terapêuticas, como também de produtos médicos, a cediça responsabilidade civil do médico cede lugar à responsabilidade coletiva e solidária dos intervenientes na promoção da saúde, a impor a inversão do onus probandi. O Direito médico cede lugar ao Direito da medicina, cujas especialidades cada vez mais implicam uma responsabilidade por prestações determinadas, como obrigações de resultado e não de meios.

$\mathrm{Na}$ Itália, por exemplo, temos o dano à pessoa, no qual se inclui o dano à saúde, como bem jurídico da personalidade, igualmente denominado dano biológico, por força do que determina o art. 32, da Constituição, que declara que "a República tutela a saúde como fundamental direito do indivíduo". O dano biológico vem caracterizado como uma injusta lesão da integridade psicofísica da pessoa, que incide sobre o valor homem em toda a sua dimensão concreta, segundo Gianini (II danno allá persona come danno biologico. Milano, 1986).

O dano biológico na moderna doutrina italiana não se confunde com o dano patrimonial e extrapatrimonial clássico, por se enquadrar em uma categoria autônoma, não patrimonial em sentido lato. Trata-se da tutela da pessoa in concreto, na valorização de um estado de saúde concretamente atribuído à vítima da lesão e que encontra o seu fundamento na própria intangibilidade da pessoa humana, ou seja, nos pilares que informam os direitos da personalidade. ${ }^{(20)}$

Não é sem razão que a regra contida no art. $5^{\circ}$ do Código Civil italiano e que inspira o art. 11 do novo Código Civil brasileiro não oferece mais soluções satisfatórias perante as novas diretivas que informam os atos de disposição do próprio corpo, notadamente em face do nosso atual diploma que excepciona os atos de disposição em face "dos casos previstos em lei". O jurista italiano Maurizio Paganelli, em seu prestigioso trabalho "Diritti Della Personalità. L'individuo e il grupo", com muita propriedade, atenta para o fato de que a aceleração de biotecnologia resulta na proteção de novos bens jurídicos a serem tutelados, considerando o corpo humano como um "tutt'único", em sua unidade funcional, pois, sendo defesa toda comercialização de partes do corpo humano, tecidos, órgãos etc., adverte: "I asporto, la riproducibilità, lo sfrutamento, la commercializzazione di parti del corpo non può mettere in discussione il diritto assoluto (di libertà) sul proprio corpo ed il fascio di diritti (della personalità) a tutela della propria integrità, dgnità e via discorrendo. Ma è altrettanto vero che la manipoazione di tessuti biologici, di cellule somatiche e germinali, di organi a fini di trapian-

(20) Danno Biológico e Danno Psicológico. Coord. Daniela Pajardi. Milano: Giuffrè, 1990, p. 51. 
to, di maternità di sostituzione od altro, impongono problemi di inquadramente giuridico ai quali ildoppio sbarramento, dettato dall'art.5 c.c. (Che vieta gli atti de disposizione del proprio corpo Che cagionino una diminuzione permanete dell' ordine pubblico od al buon costume) può non offrire soluzione soddisfacenti".(21)

Importa observar que o Conselho da Europa adotou pelo seu Comitê de Ministros, em 19 de novembro de 1996, assinada em Oviedo em 4 de abril de 1997, a Convenção dos direitos do homem e da Biomedicina, tendo por objeto a proteção dos direitos do homem e da dignidade do ser humano relativa às aplicações da biologia e da medicina, em que os interesses e 0 bem-estar do ser humano deverão prevalecer sobre o interesse exclusivo da sociedade ou da ciência, como o seu primado, com igualdade de acesso aos cuidados da saúde, ou seja, segundo a Convenção, propondo serviços e intervenções de diagnóstico, preventivas, terapêuticas, reeducativas, no sentido de melhorar o estado de saúde de uma pessoa ou aliviar o seu sofrimento, em acesso eqüitativo. Já entre nós, o novo Código Civil, que entrou em vigor em janeiro de 2003, marca profundo retrocesso, descurando dos caracteres fundamentais dos direitos da personalidade ou da pessoa humana, ocasião propícia para uma reformulação de seus princípios básicos, notadamente em seu art. 13, em que a simples "exigência médica" é causa excludente de responsabilidade por atos de disposição do próprio corpo, quando importar diminuição permanente da integridade física ou contrariar os bons costumes, em caso de transplante, previsto em lei especial, consoante o seu parágrafo único, olvidando, assim, os avanços da biotecnologia e o transplante, não só de órgãos e tecidos, como de células etc., além da comercialização de produtos derivados de sangue e de plasma, nessa amplitude de fatos jurídicos.

Importa esclarecer que não cabe alinhar em um Código casos específicos de atos de disposição de partes do corpo humano, envolvendo inseminação in vitro, clonagem, maternidade de substituição, experimentação humana, terapia genética e tantas outras formas de intervenção sobre o corpo humano, pois de modo algum resolveria as questões que dizem respeito à

(21) In Diritto Privato Europeo. Coord. Nicolò Lipari, v. 1. Padova: CEDAM, 1997, pp. 143/163. Relata o autor o caso de J. Moore, portador de leucemia rara que doou não só partes da medula óssea, como pele, sangue, líquido seminal, para fins de pesquisa e produção de uma linha celular "imortal", realizada pela equipe médica e colocada à venda como produto farmacéutico. Com o éxito e o sucesso do tratamento de múltiplas afecções, reivindicou uma participação na sua utilização, quando a Corte de Apelação da Califómia acabou reconhecendo ao paciente "direito geral de propriedade sobre o próprio corpo", sobre a própria célula, com direito ao ressarcimento, em razão da comercialização de material biológico que havia sido doado. Com a "tecnociência", corre-se o risco de transformar o paciente em "sócio" na venda de produtos biotecnológicos, com base no interesse tutelado, diante do conflito entre a absoluta ou relativa indisponibilidade de partes do corpo humano. 
salvaguarda dos direitos essenciais da pessoa humana à luz do direito privado, que estão, na verdade, a reclamar uma reconstrução sistemática de seus princípios, soltando-se da sua estrutura paradigmática de um direito subjetivo modelado em torno de um direito de propriedade (jus in se ipsum), na busca do justo, na alteridade que se reclama em face de experiência concreta, fundada na essência humana e jamais racionalista, diante de uma proteção incisiva e difusa, ou, como diz Rescigno, coincidindo com a experiência de vida moral e social do ser humano.(22)

Na verdade, são esses atos e fatos jurídicos que interessam ao Direito Civil como Direito Constitucional, na sua microfenomenologia, repetindo $R$. Limongi França, como ciência do fato, uma vez que o próprio Direito Constitucional está adstrito aos ditames civilísticos relativamente à criação e desfazimento do fato e ato jurídico, "como particularmente ao que concerne aos seus defeitos e nulidades".(23) Nula, portanto, toda disposição e limitação voluntária que comprometa a saúde (bem jurídico da personalidade), contrária aos preceitos de ordem pública e aos bons costumes. É o que se resume na tutela da vida como bem supremo e essencial da pessoa humana.

Não é sem razão que recentemente a Organização Mundial de Saúde - OMS alertou sobre os efeitos da mundialização (impropriamente denominada "globalização") com impactos imediatos sobre os sistemas de saúde e as políticas de saúde ao lado de efeitos indiretos que se exercem sobre 0 setor da saúde diante da economia nacional, principalmente sobre a nutrição e condições de vida, a impor uma proteção sanitária eficaz. ${ }^{(24)}$

Isto posto, o Direito Civil da Saúde não se resume no estudo da legislação aplicável, v.g., ao saneamento ambiental nos assentamentos urbanos, ao saneamento das edificações com normas específicas, ao saneamento da poluição ambiental, bem como das normas de promoção e preservação da saúde nas ações de vigilância sanitária e sua repressão e tantos outros dispositivos esparsos, que se circunscrevem num cipoal de portarias e resoluções a demandar uma consolidação de suas normas para um futuro Código Sanitário Nacional.

Em face desse abrangência do Direito Civil da Saúde, trazemos o magistério de Helita Barreira Custódio que, com a seriedade que the é peculiar, demonstra com clareza a importância do Direito Sanitário como ramo do Direito Positivo e integrante do sistema jurídico brasileiro, ao lado do Direito Agrário e Ambiental, embora autônomos, interdisciplinares e multidisciplina-

(22) Apud PAGANELLI, Maurizio, op. cit., p. 145.

(23) FRANÇA, R. Limongi, op. cit., pp. 192/193.

(24) Bulletin - OMS, Recueil d'articles n. 6, 2002, p. 37. 
res, garantidos constitucionalmente, cujas palavras merecem ser transcritas: "Quanto ao Direito Sanitário, define-se como um conjunto de princípios e normas gerais, especiais, complementares e excepcionais, de caráter obrigatório, impostos, coercitivamente, pelo Poder Público competente e regulador das ações e dos serviços públicos de saúde, individual, coletiva ou publicamente considerada, mediante obrigatório planejamento compreendido de medidas regulamentares, fiscalizatórias, controladoras e preventivas, por parte do Poder Público, bem como de planos de adequada execução diretamente da Administração Pública ou através de pessoas físicas ou jurídicas de direito privado, obedecido, além de outros requisitos, o atendimento integral, com prioridade para atividades preventivas, a execução de ações e serviços de vigilância sanitária, epidemiológica, de saneamento básico, de fiscalização e controle de alimentos e bebidas em geral, de substâncias e produtos psicoativos, tóxicos, radioativos, de proteção do meio ambiente saudável, dentre outros objetivos e atribuições essenciais à promoção, proteção, recuperação, melhoria e preservação da saúde pública e à conservação da vida. O Direito Sanitário, implícita e expressamente previsto nas normas constitucionais anteriores (21), foi, em razão das progressivas exigências notadamente socioeconômicas e sanitário-ambientais, reafirmado, ampliado e consolidado pela vigente Magna Carta. Evidentemente, a Constituição de 1988, além de garantir a inviolabilidade do direito à vida, incluída a inviolabilidade do direito à saúde (art. $5^{\circ}$ ), e de definir a competência concorrente da União, dos Estados e do Distrito Federal (incluída a dos Municípios, implícita e expressamente, por se tratar de matéria de interesse local, CF, art. $24, \mathrm{XII} \mathrm{c} / \mathrm{c}$ art. 30,1$)$ para legislar sobre a proteção e defesa da saúde (art. 24, XII) e a competência comum de tais unidades para cuidar da saúde e assistência pública (art. 23, II), introduziu, de forma inovatória, relevantes princípios e normas reguladoras de um conjunto de ações e serviços de iniciativa dos poderes públicos e da sociedade, destinados a assegurar os direitos relativos à saúde, à previdência e à assistência social (CF, art. 194), bem como a garantir a promoção, a proteção, a recuperação, a melhoria e a conservação da saúde, definida como direito de todos e dever do Estado (União, Estados, Distrito Federal e Municípios), além da prioridade para as atividades preventivas, em caráter permanente (CF, arts. 196 a 200), tudo visando a proteger a vida presente e futura como inviolável direito fundamental da pessoa humana, individual, coletiva e publicamente considerada". ${ }^{(25)}$

Esclarecendo em nota: "(21) Em nosso Direito Positivo, as primeiras normas fundamentais de Direito Sanitário foram previstas na Constituição do Império de 1824, com a garantia da inviolabilidade dos direitos civis e

(25) Direito à Saúde e Problemática dos Agrotóxicos. In Revista de Direito Sanitário. São Paulo, v. 2, n. 3, nov. 2001, pp. 21/22. 
da saúde dos cidadãos (art. 179, XXIV). Na primeira Constituição da República de 1891, as normas sobre saúde foram previstas implicitamente na declaração de direitos (art. 72). Tais normas, a partir da Constituição de 1934, constantes do Capítulo dos Direitos e Garantias Fundamentais (CF/ 1934, art. 113; CF/1937, art. 122), passaram a constituir matéria de competência legislativa, ora concorrente da União e dos Estados para 'cuidar da saúde e assistência públicas' (CF/1934, art. 10, II), ora privativa da União para estabelecer 'normas fundamentais da defesa e proteção da saúde, especialmente da saúde da criança' (CF/1937, art. 16, XXVII). Em progressiva evolução, a partir da Constituição de 1946, as normas sobre saúde, agora expressamente garantidas na 'inviolabilidade dos direitos concernentes à vida' (CF/1946, art. 141; CF/1967, art. 150; EC/1969, art. 153; CF/ 1988 , art. $\left.5^{9}\right)$, foram reafirmadas como matéria de competência privativa da União (CF/1946, art. 5, XV, b)"..(26)

Concluímos com Konrad Hesse, em sua obra "Derecho Constitucional e Derecho Privado",(27) ao demonstrar que os preceitos constitucionais relativos aos direitos fundamentais estabeleceram uma ordem objetiva de valores a qual deve reger todos os âmbitos do Direito. Isto posto, não tem mais razão de ser a idéia de que o Direito Privado regula as relações dos particulares sob o ponto de vista da liberdade individual, à margem das relações políticas e constitucionais. ${ }^{(28)}$

Segundo Konrad Hesse, o necessário não é uma modificação do Direito Constitucional vigente, mas um desenvolvimento que leve mais em conta as particularidades da realização dos direitos fundamentais nas relações jurídico-privadas. Nas suas palavras, ao legislador do Direito Privado corresponde constitucionalmente a tarefa de transformar o conteúdo dos direitos fundamentais, de modo diferenciado e concreto, em Direito imediatamente vinculante para os participantes de uma relação jurídico-privada. ${ }^{(29)}$ Por sua vez, os meios de tutela devem ser distintos, segundo o âmbito material em questão, aos da tutela diante dos atos dos poderes públicos. Do mesmo modo, os meios de tutela dos direitos fundamentais devem ser garantidos em face das lesões e perigos procedentes do âmbito não estatal, tal como acontece com os planos de saúde, em que as empresas assumem a garantia de um direito eminentemente social, tomando a posição jurídica tradicionalmente conferida ao Estado.

Cabe ao Direito Civil Sanitário, ou melhor dizendo, ao Direito Civil da Saúde, que no âmbito privado é direito da personalidade, a efetiva tutela da pessoa humana em sua existência.

(26) Idem, ibidem, p. 22.

(27) Trad. Ignácio Gutiérrez. Madrid: Civitas, 1995, pp. 62-63.

(28) Idem, ibidem, p. 57.

(29) Idem, ibidem, p. 57. 
Em suma, não é sem razão que o Código Civil português considera nula toda a limitação voluntária aos direitos da personalidade. $O$ Direito Civil da Saúde tem por finalidade "deixar fluir", utilizando a expressão de Konrad Hesse, o conteúdo jurídico da saúde como direito fundamental, dentro de uma nova configuração desse direito, que tem apresentação apenas como diretriz programática, sem qualquer força vinculante ao aplicador do Direito. 